


\title{
PAISAJES CULTURALES DEL AGUA
}

\author{
Paula Orduña, Melisa Pesoa y Joaquín Sabaté
}

En diversas ocasiones Pietro Laureano nos ha explicado como una serie de gotas de agua, primorosamente conducidas, pueden dar lugar a un pequeño oasis, al inicio, o convertirse después, en asentamientos como Petra, Shibaz, o tantos otros monumentos de piedra y arena, que encontramos en Capadocia, en el Sahara o en Yemen.

Incluso el más remoto desierto, monumento de la naturaleza, puede devenir un rico paisaje cultural incorporando el trabajo humano, siempre que se puedan captar y conducir hábilmente unas pocas gotas de agua, mediante sofisticadas canalizaciones esculpidas perseverantemente en la tierra.

Son estas mismas gotas de agua las que están a la base de tantos paisajes culturales, epopeyas seculares en diversos rincones del planeta, desde Gobi al Yucatán, pasando por los qanats que confirieron vida a tantas ciudades persas; o mucho más cerca, en Mattera al Sur de Italia, en La Geria de Lanzarote, o en la Sierra de Tramontana a poniente de Mallorca. 
Esta última constituye una singular construcción, resultante de despedregar durante generaciones un territorio agreste; utilizar de forma sensible y sostenible la piedra que sobraba, dispuesta sin argamasa; aterrazar primorosamente un terreno abrupto y hacerlo cultivable, al retener el agua y la escasa tierra vegetal existente. En la Sierra de Tramontana, como en tantos otros paisajes del agua, se construyen pozos, fuentes de minas, casas de nieve, molinos, aljibes, almazaras, carboneras, hornos de cal, cuevas o cabañas y se encauza el recorrido del agua empedrando márgenes de torrentes o construyendo canales, acequias, norias y acueductos. También se facilita el movimiento de las personas a través de caminos de piedra, paredes, escaleras y rampas, cruces de término, puentes y varaderos cerca del mar.

Todo esto configura un lugar único, un paisaje excepcional por al esfuerzo durante siglos de sus habitantes, la conjunción de condiciones naturales singulares y de usos respetuosos con el territorio. Este esfuerzo se caracteriza por un claro hilo conductor: el aprovechamiento cuidadoso de la piedra para modelar terrazas fértiles; facilitar el movimiento del agua y de las personas; levantar pequeños refugios o monumentos. La Sierra muestra la huella del trabajo sobre el territorio, ese memorial al trabajador desconocido.

Son numerosos y bien diversos este tipo de paisajes culturales repartidos por todo el mundo, pero muchos tienen el común esa esforzada huella del trabajo acumulado sobre el territorio; el obligado ingenio de tantas generaciones para captar, conducir y aprovechar sabiamente esas gotas de agua, y por todo ello atesoran la extraordinaria belleza del esfuerzo hecho paisaje.

Desde siempre el agua ha sido el elemento clave en la relación entre el hombre y la naturaleza. Los asentamientos surgen y crecen allí donde se dispone o es posible captar esas gotas de agua, desde Mesopotamia a la Amazonía, pero asimismo en los desiertos. El agua no es sólo un recurso esencial para la vida, sino que ha sido, y es aún, vía de comunicación, fuente de trabajo y de generación de energía, razón de ser de las grandes transformaciones de la humanidad, como la primera industrialización, y, fundamentalmente, constructora de paisaje.

Los paisajes configurados alrededor de este elemento muestran aspectos en común, a la vez que descubren las múltiples formas de identificación de este recurso, escaso y muy 
preciado en tantas geografías. El agua está presente en la mayoría de paisajes de forma explícita o tácita. Podemos percibirla como elemento morfológico, como componente funcional primordial del sistema paisajístico, como materia prima y recurso básico o como representación simbólica.

Las características de estos paisajes dependen del estado o forma que adopta el agua: corriente o estancada, subterránea o superficial, abierta o confinada, y de su escala. A menor escala geográfica suele incluir estructuras y tramas de interés, especialmente rurales y sistemas y elementos hidráulicos, que en muchos casos se caracterizan por su linealidad. A mayor escala el interés se acrecienta con artefactos específicos (azudas, molinos, puentes, centrales hidroeléctricas, etc.).

No es extraño pues, que en la pasada edición del Seminario Internacional de Urbanismo, se presentaran diversas ponencias que tenían en común este hilo conductor, mostrarnos el agua como modeladora de paisajes. Entre ellas hemos escogido unas pocas que nos permiten reflexionar en este nuevo número de Identidades, sobre el valor del agua como elemento generador de paisajes culturales.

En los diferentes artículos aquí recogidos podremos apreciar roles diversos del agua, que van desde su cometido como vía de comunicación, elemento productivo o motor de una transformación que genera nuevos paisajes.

Los dos primeros textos, de Paula Orduña y Manuel Julià, analizan un elemento tan relevante como el Canal du Midi, un brazo de agua que sirvió para conectar en el siglo XVII el Océano Atlántico con el Mar Mediterráneo y para irrigar miles de hectáreas, tras una verdadera epopeya técnica y la contribución anónima de veinticinco mil brazos. Arrancaba así una de las más importantes vías de transporte durante siglos, hasta que el ferrocarril primero, y las autopistas después, la condenaron a su obsolescencia.

Paula Orduña nos relata el nacimiento, ocaso y resurgir, cual Ave Fénix, en las últimas décadas, de esta línea de agua, al calor de su nominación como Patrimonio de la Humanidad. Pero además se fija con detalle, rigor y espíritu crítico, en un problema bien común en tantos de estos ámbitos, ricos en historia acumulada, aunque alejados de requerimientos contemporáneos, en el debate entre preservación y modernización. La gente del agua (gens de l'eau), como se reconocen los trabajadores vinculados durante 
décadas al transporte, entiende como una agresión desvirtuadora, la irrupción de las nuevas funciones de ocio y turismo, y la falta de mantenimiento de aquel saber hacer de personajes que, como Riquet y Vauban, levantaron un monumento a la ingeniería. La preservación a través de la transformación, sería el lema de tantos otros agentes locales, o responsables administrativos, que pretenden poner en valor un recurso tan importante al servicio de un nuevo impulso económico.

Manuel Julià se cuestiona la condición y el tratamiento como paisaje cultural de una infraestructura territorial que llega a trasladar más de 100.000 viajeros y 110 millones de toneladas de mercancías. Lo hace viajando desde el origen del concepto a las exigencias actuales e interrogarse por la identidad del canal, condición básica para re-proyectarlo. Las razones que llevaron a su reconocimiento (su valor tecnológico, su transcendencia histórica y su dimensión paisajística), permiten considerarlo una especie de museo lineal, aunque carece de un proyecto potente, claro y definido. Plantea una postura crítica frente al discurso oficial denunciando la substitución de la identidad propia del canal, la falta de una imagen y un relato conjunto, o la declaración top-down, sin que cale en la base social de los territorios atravesados, en la gens de l'eau, circunstancias todas ellas, que dificultan la existencia de un proyecto para el canal.

El artículo de Lidia Matías sobre los canales de Aveiro introduce el tema del agua como vía de circulación pero dentro de un entorno urbano. Así, el camino de agua viene a complementar y enriquecer los espacios públicos de la ciudad. La autora defiende que estos canales son un rasgo identitario de la ciudad y que por tanto podrían ayudar a configurar espacios públicos de calidad y mejorar la legibilidad urbana, en sintonía con los valores de la cultura local. Aunque la investigación se encuentra en estado inicial, la autora logra definir las características morfológicas principales y cómo se integran las actividades cotidianas con los canales, lo cual le ha de permitir en el futuro definir estrategias para su mejor integración en la ciudad.

El texto de Carme Carcaño nos presenta las huellas del agua en la ciudad transformadas en jardines metropolitanos. Ríos y rieras (o arroyos) conforman parques que ayudan a conectar la ciudad con la naturaleza y por tanto aportan un valor añadido al espacio libre: éste ya no es solamente un espacio no construido cualificado sino que nos muestra un paisaje que 
asoma y ayuda a configurar un nuevo tipo de ciudad, que la autora analiza cuidadosamente, con la intención de diseñar pautas de actuación en los espacios fluviales.

Antonio Sahady, José Bravo y Carolina Quilodrán llevan tiempo estudiando cómo el aprovechamiento del agua da lugar a la construcción de ingeniosos instrumentos como las azudas, ruedas que elevan el agua hasta los sembradíos y que a su vez son elementos fundamentales en la identidad del paisaje de Lamahue, en Chile, donde las construcciones de adobe se acomodan a la traza de los canales. Su proyecto de investigación no tan solo inventaría un conjunto de recursos patrimoniales amenazados por su desconocimiento, sino que ha contribuido a que sean reconocidas como Monumento Histórico. La contribución de estas ruedas a irrigar terrenos yermos, ha permitido a los campesinos ampliar sus paños agrícolas de huertos, maizales y árboles frutales. Cada una de las azudas presenta características diversas en la composición de la estructura de la rueda, en las llantas, paletas y cangilones, así como en las canaletas que conducen el agua elevada. Aunque su valor está en directa relación con su hábitat, con el efecto social que irradian y el beneficio económico que implica su actividad de fecundar terrenos otrora infértiles, estos artefactos constituyen verdaderos agentes transformadores del medio natural, sabios e ingeniosos constructores de paisaje.

Marta Somoza presenta un estudio sobre un entorno rural cuyo principal objetivo es identificar las estructuras agrícolas tradicionales, asociadas a un modo singular de agrupamiento de las viviendas, muy característico del paisaje gallego, para que, a partir de su comprensión, se puedan establecer herramientas de planeamiento y gestión. El agua es parte del sistema total que configura un tipo de explotación en terrazas, para frenar precisamente su velocidad y evitar la erosión y pérdida de nutrientes. Como concluye la autora, la riqueza productiva de este ámbito, donde las formas generadas por el sistema tradicional y su entendimiento como un ente polifacético siguen siendo la clave de su potencialidad, se le añade el valor que presentan estos territorios como paisajes de plasticidad líquida, atractivos a los sentidos, y con una intensa capacidad de permanecer en la memoria, convirtiéndolos en signo de identidad y referente de una comunidad.

La construcción de un embalse constituye obliga a relocalizar a los pobladores del antiguo Fayón y da origen a uno de los poblados de colonización que Marc Darder analiza. José Borobio culmina aquí una fecunda carrera en el Instituto Nacional de Colonización y afronta 
un reto añadido. ¿Cómo mantener la identidad, la memoria del viejo núcleo vinculada al río, al desplazarse tierra adentro? Nos descubre, además, el valor de una trayectoria, el último de un conjunto de proyectos de notabilísima calidad, que a pesar del control abrumador del régimen y del Instituto, aprovecha sus escasas rendijas, para introducir destellos de modernidad. Nos muestra asimismo la intensidad con que su autor reflexiona una y otra vez, y con materiales muy modestos, sobre la construcción de la urbanidad.

Mucho se ha escrito sobre el paisaje de las colonias industriales a lo largo de los ríos Ter, Freser y Llobregat. Pero en el último artículo, Marta Castañé nos descubre que cuando estas colonias empiezan a colonizar el valle del Ter, el territorio no estaba encontraba vacío. La agricultura había dejado unas preexistencias que condicionan la posición de las fábricas. Se trata en definitiva, de un proyecto territorial basado en el uso del agua y en el rendimiento económico que se inicia muchos años antes. Su artículo aporta una mirada detallada a los antecedentes de la colonia industrial, de la mano de grandes viajeros y estudiosos, como Pla, Zamora y Madoz, o de los libros de concesiones, recorremos ese territorio preindustrial y descubrimos un importante número de molinos fluviales, tan sabiamente dispuestos, que allanarán el camino a las futuras colonias.

La historia nos muestra como el agua ha sido siempre un elemento capaz de aglutinar considerables esfuerzos con la finalidad común de su aprovechamiento: desde el cultivo de arroz en bancales donde todos los productores han de trabajar para sacar el máximo partido al recurso; pasando por la lucha de un país, como Holanda, por construir su geografía a costa de ríos y mares, o de una ciudad por sobrevivir en el agua, como en el caso de Venecia; hasta la construcción de canales para la navegación y el riego, donde de la correcta administración del recurso depende la supervivencia de una zona. El manejo del agua exige un esfuerzo colectivo y quizás sea ese su principal valor en la construcción de un paisaje cultural.

A su vez, ya sea con un trabajo más elaborado, o en una disposición más natural, el agua como parte de los paisajes culturales plantea una complejidad añadida que tiene que ver con su mantenimiento no sólo como valor patrimonial sino asimismo como recurso natural. Esta dualidad que presenta es una de sus principales potencialidades (y dificultades) a 
la hora de abordar su gestión. La concienciación y la educación son aquí dos elementos centrales.

Al reconocer, poner en valor, proyectar y gestionar estos paisajes en torno al agua, se nos plantean desafíos vinculados a los cambios de usos o a las intervenciones de modernización de valiosos sistemas tradicionales. Es entonces, y algunos de los textos aquí recogidos reflexionan sobre ello, cuando el patrimonio se convierte en argumento central para debatir acerca de la estricta conservación o de la razonada transformación de elementos que conforman tantos de nuestros paisajes contemporáneos. 